\title{
The correlation of BER protein, IRF3 with CD8+ $T$ cell and their prognostic significance in upper tract urothelial carcinoma
}

This article was published in the following Dove Press journal: OncoTargets and Therapy

\author{
Lin-ang Wang ${ }^{1} *$ \\ Bo Yang ${ }^{2, *}$ \\ Wen Rao $\mathbb{D}^{2}$ \\ Hualiang $\mathrm{Xiao}^{3}$ \\ Dong Wang ${ }^{2}$ \\ Jun Jiang'
}

'Department of Urology, Daping Hospital \& Army Medical Center of PLA, Third Military Medical University (Army Medical University), Chongqing 400042, People's Republic of China; ${ }^{2}$ Cancer Center, Daping Hospital \& Army Medical Center of PLA, Third Military Medical University (Army Medical University), Chongqing 400042, People's Republic of China; ${ }^{3}$ Department of Pathology, Daping Hospital \& Army Medical Center of PLA, Third Military Medical University (Army Medical University), Chongqing 400042, People's Republic of China

*These authors contributed equally to this work
Correspondence: Jun Jiang

Department of Urology, Daping Hospital \& Army Medical Center of PLA, Third Military Medical University (Army Medical University), Chongqing 400042, People's Republic of China

Tel +86236875 715।

Fax +86 2368894062

Email jiangjun_64@I63.com
Objectives: Tumor-infiltrating lymphocytes (TILs) play a crucial role in anti-tumor immunity. Basic studies have found that stimulator of interferon genes (STING), activated by sensing DNA damage, plays a role in recruiting and activating TILs in tumors. However, the correlation between base excision repair (BER) pathway, STING pathway and TILS and their effect on prognosis in upper urinary tract urothelial carcinoma (UTUC) are still unclear. The aim of this study was to investigate the prognostic effect of those proteins expression for disease-free survival (DFS) and overall survival (OS) and explore the correlation between these makers.

Methods: We evaluated immunohistochemical expression of BER pathway (APE1, NTH1, OGG1, XRCC1, pol $\beta$ ), STING pathway (STING, IRF3), TILs (CD4, CD8, CD20) and PDL1, PD-L2 in 88 UTUC patients to determine the predictive significance in DFS, OS and the correlation between them.

Results: We found that interferon regulatory factor3 (IRF3) (HR: 0.451, 95\% CI 0.243-0.837, $p=0.024$ ) and CD8 (HR: $0.522,95 \%$ CI $0.295-0.926, p=0.014)$ are independent prognostic factors for DFS, APE1 (HR: 1.932, 95\% CI 1.005-3.714, $P=0.048$ ), pol $\beta$ (HR: $2.620,95 \%$ CI 1.373-5.000, $P=0.003$ ), CD8 (HR: 0.323, 95\% CI 0.151-0.693, $P=0.004$ ) were independent prognostic factors for OS. A model consisting of stage, grade, lymphovascular invasion and expression of APE1, pol $\beta$, IRF3, CD4, CD8 that predicts 3-year OS. Furthermore, DNA damage repair protein pol $\beta$ is associated with $\mathrm{CD} 8+\mathrm{T}$ cells in TME.

Conclusion: We found that DNA damage, IRF3 and TILs are independent predictors for prognosis. We also provided clinical evidence that DNA damage repair-activated STING pathway can induce the recruitment and activation of TILs, which is consistent with preclinical models.

Keywords: BER, IRF3, tumor-infiltrating lymphocytes, prognosis

\section{Background}

Upper tract urothelial carcinoma (UTUC) is a malignant tumor originating from urothelial carcinoma of the renal pelvis and ureter, accounting for approximately $5-10 \%$ of all urothelial malignancies. ${ }^{1}$ Although UTUC has the same origin with urothelial carcinoma of the bladder, its biological behavior is significantly different from that of bladder cancer, showing higher malignancy and poorer prognosis. ${ }^{2}$ At present, the main variables defining prognosis are histopathological stage and grade, ${ }^{3-5}$ but patients with the same pTNM stage and same grade of UTUC often demonstrate considerable discrepancy in recurrence and overall survival (OS). Thus, molecular markers that are more precise are needed. 
Previous studies have shown that infiltrating immune cells, especially lymphocytes, play an important role in anti-tumor immunity and the presence of tumor-infiltrating lymphocytes (TILs) has been associated with favorable prognosis in several neoplasms. ${ }^{6,7}$ In tumor, type I interferon (IIFN) is responsible for recruitment and activation of lymphocytes, ${ }^{8,9}$ recent evidence suggests stimulator of interferon genes (STING) signaling as one of the key pathways to trigger IFN production in cancerous conditions. ${ }^{10-12}$ STING is an adapter protein, which gets activated by cyclic dinucleotides, generated by cyclic guanosine monophosphateadenosine monophosphate synthase (cGAS), which in turn is directly activated by cytosolic double-stranded DNA (dsDNA). STING then signals to the TANK binding kinase 1 (TBK1)/interferon regulatory factor3 (IRF3) axis to upregulate type I interferon production. ${ }^{13-15}$

Genomic instability, rapid proliferation of tumor cells and DNA damage repair (DDR) deficiency are the main sources of dsDNA. ${ }^{16}$ Normally DDR can repair DNA damage in many different forms, such as nucleotide excision repair, mismatch repair (MMR), homologous recombination (HR), non-homologous end-joining, base excision repair (BER), and translation synthesis. ${ }^{17}$ Numerous studies have found that DDR is associated with tumor prognosis, tumors carrying defects in DNA MMR accumulate high levels of mutations, a feature linked to rapid tumor progression and acquisition of drug resistance but also favorable prognosis and response to immune-checkpoint blockade. ${ }^{18}$ In prostate cancer, relevant studies have identified genomic defects in DNA repair in $20-30 \%$ of advanced castration-resistant prostate cancer cases, BRCA2 gene alterations are particularly prevalent and are correlated with poor prognosis as well as poor responses to systemic therapy for castration-resistant prostate cancer. ${ }^{19}$ Teo's study claimed that DDR alterations are independently associated with response to PD-1/PD-L1 blockade and platinum-based treatments in patients with advanced urothelial carcinoma. ${ }^{20,21}$

The BER pathway is responsible for repairing most endogenous DNA damage, including deamine depurine alkylation and excessive oxidative damage resulting in base loss. ${ }^{22,23}$ BER is a highly conserved pathway in different species, mainly involving 5 enzyme reaction processes, including APE1, OGG1, XRCC1, pol $\beta$ and NTH1. ${ }^{24-26}$ It has been confirmed that APE1 is highly expressed in tumors and is associated with resistance to platinum therapy and radiotherapy. ${ }^{27,28}$ It is also found that pol $\beta$ is highly expressed in tumors, but $\mathrm{XRCC} 1$ is low expressed in gastric, lung and cervical cancers and is associated with invasiveness and poor prognosis of tumors. $^{29}$

The significance of the proteins expression of BER pathway and STING pathway in UTUC has not been reported. Whether the expression level of those proteins can be used as prognostic makers of UTUC remains unclear. In this study, the correlation between BER pathway, STING pathway, and TILS and its effects of UTUC prognosis was evaluated by immunohistochemistry.

\section{Methods}

\section{Patients}

We reviewed the records of 91 patients with primary UTUC from January 2014 to January 2017 in the Third Affiliated Hospital of Third Military Medical University. The patients did not receive any chemotherapy or radiation therapy before surgery. One patient was not included in this study due to perioperative death and another 2 cases due to unqualified formalin-fixed paraffin-embedded tissue samples. Finally, clinical and pathological data of 88 patients were analyzed. Radical nephroureterectomywith the removal of the bladder cuff was the most common procedure (69), segmental ureterectomy was performed in 10 patients, and nephrectomy was performed in 9 patients. Intravesical instillation after surgery was performed in 83 patients, and the intravesical agents including gemcitabine, epirubicin, pirarubicin. Eight patients received adjuvant chemoradiotherapy, which was platinumcontaining regimen. At the end of follow-up, 36 patients relapsed and 26 died.

Post-operation cystoscopy was suggested every 3 months for 2 years and every 6 months for the next 2 years and annually thereafter. Other follow-ups consisted of urine cytology, abdominal CT scan and ultrasonography. The study methodologies conformed to the standards set by the Declaration of Helsinki. Approval of the study was obtained from the institutional review board of the Third Affiliated Hospital of Third Military Medical University No. 2018-108 and written informed consent was waived as there were no conflicts of interest or damage to patients.

\section{Immunohistochemical (IHC)}

Tissue microarrays were constructed as described. ${ }^{30} \mathrm{HE}$ staining was used to determine the tumor location to obtain the tumor tissue accurately, core samples diameter is $3 \mathrm{~mm}$, which were transferred to a recipient paraffin block using a tissue microarrayer (Minicore). Consecutive $3 \mu \mathrm{m}$ thick slices were 
cut from FFPE tumor tissue. Paraffin wax was melted at $60^{\circ} \mathrm{C}$ for $6 \mathrm{hrs}$, subsequently, slides were deparaffinized in xylene and rehydrated in declining dilutions of ethanol. For HIER, slides were incubated in $10 \mathrm{mM}$ sodium citrate (SigmaAldrich, St. Louis, MO, USA) containing 0.05\% Tween 20 (Sigma-Aldrich) at pH 6.0 or in $10 \mathrm{mM}$ tris (hydroxymethyl) aminomethane (Merck Millipore, Darmstadt, HE, DE) and 1 mM EDTA (Sigma-Aldrich) containing 0.05\% Tween 20 at pH 9.0 and heated up in pressure cooker. Consequently, slides were cooled down to room temperature (RT). Endogenous peroxidase activity was blocked with $0.3 \%$ hydrogen peroxide (Merck Millipore) in PBS for $10 \mathrm{mins}$ at RT in the dark. Primary antibodies (Table S1) were incubated for overnight at $4^{\circ} \mathrm{C}$ in a humidified chamber. Afterwards, biotinylated rabbit anti-mouse $\mathrm{IgG}$ /anti-rabbit $\mathrm{IgG}$ secondary antibody was applied for 30 mins at $37^{\circ} \mathrm{C}$. Diaminobenzidineshowed color, subsequently hematoxylin counterstain.

Immunoscore was independently assessed by two pathologists (WD, XHL) who were blinded to the patients' clinical outcomes. In cases with discrepant results, the slides were reviewed under a multi-head microscope and discussed to determine the final score. Semiquantitative assessment of positivity was performed using the following formula: staining intensity $\times$ positive cell rate. Staining intensity was stratified from 0 to 3 ( 0 , no staining; 1 , slight staining; 2, medium staining; and 3, strong staining). The scale of positive cell rate was identified as follows: 1, number of stained cells $<1 / 3 ; 2,1 / 3 \leq$ number of stained cells $<2 / 3 ; 3$, number of stained cells $\geq 2 / 3$. The final total score was between 0 and 9 . We defined low expression as below 4 points and high expression as above 5 points. Patients were divided into high- and low-expression groups based on the expression score. The expression of PD-L1 was classified into high- and low-expression according to non-expression and expression (Figure S1).

\section{Statistics}

Disease-free survival (DFS) was measured from the date of the initial treatment to the date of diagnosis of locoregional recurrence or distant metastasis. OS was measured from the date of the initial treatment to the date of death.

Data analysis was performed using SPSS (SPSS, version 21) and GraphPad Prism 7 (GraphPad Software, Inc., La Jolla, CA, USA). Cumulative survival probabilities were estimated using the Kaplan-Meier method, and differences between survival rates were tested for significance using the log-rank test. HRs and 95\% CIs were estimated for each variable. All tests were two-sided with a $95 \% \mathrm{CI}$ and $P<0.05$ considered significant. HRs and corresponding 95\% CIs were plotted with R-package "forestplot" (version 1.74). Prognostics models were computed with an adaptive elastic-net approach for censored data using the R-package "rms" (version 5.1-3.1) and are illustrated by nomograms. For validation of the nomogram, we assessed the discrimination ability using Harrell's concordance index (c-index). The model-predictor was further dichotomized into a high-risk and low-risk group to illustrate the impact of each final model on clinical outcome, which is illustrated by Kaplan-Meier survival estimates. Kendall correlation coefficients for IHC maker and clinical data were calculated with intrinsic $\mathrm{R}$ commands and R-package "corrplot" (version 0.84). P-values of the "corrplot" were corrected according to the false discovery rate.

\section{Results \\ Clinical and pathological characters and IHC makers features of UTUC}

A total of 88 patients with UTUC were included in this study. The follow-up time was 2-60 months, and the median follow-up time was 23 months. Of 88 patients, 51 were pelvic cancer and 37 were ureteral cancer, there were 37 cases of non-muscles invasive urothelial carcinoma and 51 cases of muscles invasive urothelial carcinoma. There were 8 cases with positive lymph nodes, 17 with lymphovascular invasion, 17 with lowgrade and 71 with high-grade papillary urothelial carcinoma. Detailed characteristics of patients are shown in Table 1. Immunohistochemical results showed that APE1 (59/88), NTH1 (52/88) were high expressed, and OGG1 (70/88), STING (69/88), PD-L1 (67/88) were low expressed. There was a difference in CD20 expression between renal pelvic cancer and ureteral cancer. Compared with ureteral cancer, renal pelvic cancer had more infiltration of $\mathrm{CD}_{2} 0^{+} \mathrm{B}$ cells. Low-grade and high-grade urothelial carcinomas displayed PD-L2 expression difference. High-grade urothelial carcinomas expressed higher PD-L2. Muscle invasive urothelial carcinoma shows less of $\mathrm{CD} 8+\mathrm{T}$ cells infiltration. Detailed results are shown in Table 2.

Kaplan-Meier analysis and log-rank tests demonstrated that low expression of IRF3 ( $p=0.0091)$ CD4 $(p=0.0075)$, CD8 $(p=0.0086)$ and high expression of pol $\beta(p=0.0471)$ were associated with shorter DFS (Figure 1); high expression 
Table I Clinicopathological features of patients with UTUC

\begin{tabular}{|c|c|}
\hline Clinical and pathological characters & $\mathbf{N}(\%)$ \\
\hline Median age, years (range) & $70(47-91)$ \\
\hline \multicolumn{2}{|l|}{ Sex, n (\%) } \\
\hline Male & $60(68.18)$ \\
\hline Female & $28(3 \mid .82)$ \\
\hline \multicolumn{2}{|l|}{ Smoking, n (\%) } \\
\hline Yes & $42(47.73)$ \\
\hline No & $46(52.27)$ \\
\hline \multicolumn{2}{|l|}{ Tumor side, $\mathrm{n}(\%)$} \\
\hline Left & $48(54.55)$ \\
\hline Right & $40(45.45)$ \\
\hline \multicolumn{2}{|l|}{ Tumor location, n (\%) } \\
\hline Calix or pelvis & $51(57.95)$ \\
\hline Ureter & $37(42.05)$ \\
\hline \multicolumn{2}{|l|}{ Symptom, n (\%) } \\
\hline Hematuresis & $58(65.91)$ \\
\hline Hydronephrosis & $5(5.68)$ \\
\hline Low back pain & $22(25.00)$ \\
\hline \multicolumn{2}{|l|}{ Type of surgery, n (\%) } \\
\hline Open & $16(18.18)$ \\
\hline Laparoscopic & $72(81.82)$ \\
\hline \multicolumn{2}{|l|}{ RNU, n (\%) } \\
\hline Yes & $69(78.41)$ \\
\hline No & $19(21.59)$ \\
\hline \multicolumn{2}{|l|}{ Pathological T stage, n (\%) } \\
\hline Ta-TI & $37(42.05)$ \\
\hline $\mathrm{T} 2-\mathrm{T} 4$ & $51(57.95)$ \\
\hline \multicolumn{2}{|l|}{ Pathological N stage, n (\%) } \\
\hline $\mathrm{pNx}$ or $\mathrm{pN} 0$ & $80(90.91)$ \\
\hline $\mathrm{pNI}-2$ & $8(9.09)$ \\
\hline \multicolumn{2}{|l|}{ Tumor stage AJCC staging, n (\%) } \\
\hline 1 & $37(42.04)$ \\
\hline II & $10(11.36)$ \\
\hline III & $22(25.00)$ \\
\hline IV & $19(21.60)$ \\
\hline \multicolumn{2}{|l|}{ Tumor grade, n (\%) } \\
\hline Low & $17(19.32)$ \\
\hline High & $71(80.68)$ \\
\hline \multicolumn{2}{|l|}{ LVI, n (\%) } \\
\hline Yes & 17 (19.32) \\
\hline No & $71(80.68)$ \\
\hline
\end{tabular}

Abbreviations: RNU, radical nephroureterectomy; LVI, lymphovascular invasion.

of APE1 $(p=0.026), \operatorname{pol} \beta(p=0.001)$, and low expression of CD4 $(p=0.0042), \mathrm{CD} 8(p=0.0009), \mathrm{IRF} 3(p=0.0266)$ were correlated with poor OS (Figure 2).

\section{IRF3 and CD8+ T cells are prognostic indicators of DFS}

Firstly, we conducted a univariate Cox regression analysis for IHC markers, and found that IRF3 (HR: $0.486,95 \%$ CI $0.276-$ 0.853, $P=0.012$ ), CD4 (HR: $0.468,95 \%$ CI $0.263-0.835$, $P=0.01$ ), CD8 (HR: 0.435 95\% CI $0.235-0.805, P=0.008$ ) were related to prognosis. Furthermore, we conducted a univariate Cox regression analysis for the clinical characteristics. The clinical characteristics that contributed with statistical significance to DFS were LVI (HR: 1.925, 95\% CI, 1.0023.697, $p=0.049$ ). Additionally, we assessed a multivariable analysis for DFS by combining the marker panel and clinical variables and found IRF3 (HR: $0.451,95 \%$ CI $0.243-0.837$, $p=0.024$ ) and CD8 (HR: 0.522 , 95\% CI $0.295-0.926$, $p=0.014)$ are independent prognostic factors. The results of Cox regression analysis are snhow in Table 3.

\section{APEI, Pol $\beta$, IRF3 and CD8 are independent prognostic factors for OS}

Similar to DFS, to investigate the association impact of IHC marker and clinical characteristics with OS we conducted a univariate Cox regression analysis. The expression of APE1 (HR: $2.122,95 \%$ CI $1.110-4.058, P=0.023$ ), $\operatorname{pol} \beta$ (HR: 2.766, 95\% CI 1.466-5.215, $P=0.002$ ), IRF3 (HR: 0.496, 95\% CI 0.264-0.934, $P=0.030$ ), CD4 (HR: $0.399,95 \%$ CI 0.208-0.764, $P=0.006$ ), CD8 (HR: $0.308,95 \%$ CI $0.148-$ $0.639, P=0.002$ ), LVI (HR: $2.138,95 \%$ CI $1.063-4.301$, $P=0.033$ ), staging (HR: $1.380,95 \%$ CI $1.059-1.799$, $P=0.017$ ), pathological grading (HR: $3.050,95 \%$ CI 1.080 $8.608, P=0.035$ ) were associatedwith OS (Figure $3 \mathrm{~A}$ ). The results of Cox multivariate regression analysis showed that grade (HR: $3.059,95 \%$ CI 1.081-8.661, $P=0.035$ ), APE1 (HR: $1.932,95 \%$ CI $1.005-3.714, P=0.048$ ), $\operatorname{pol} \beta$ (HR: 2.620, 95\% CI 1.373-5.000, $P=0.003$ ), CD8 (HR: 0.323, $95 \%$ CI $0.151-0.693, P=0.004)$ were independent prognostic factors. The results of Cox regression analysis are shown in Table 4. A competing-risk nomogram was developed for the prediction of the probability of OS at 3 years (Figure 3B). This model was based on stage, grade, LVI, and expression of APE1, polß, IRF3, CD4, CD8. By calculating the total number of risk points on the nomogram, one is able to calculate the 3-year OS. The calibration plots were separately demonstrated for a 3-year OS. And the c-index of this model was 0.79 (Figure 3C). On the basis of the statistically significant model, patients were further dichotomized into high-risk and low-risk groups, which revealed a significant different OS probability between the two groups (Figure 3D). 
Table 2 Association of IHE makers expression with clinicopathological parameters

\begin{tabular}{|c|c|c|c|c|c|c|c|c|c|c|}
\hline Protein & Expression & Pelvis & Ureter & $p$ & Low grade & High grade & $p$ & $\mathbf{I}$ & II+III+IV & $p$ \\
\hline APEI & $\begin{array}{l}\text { Low } \\
\text { High }\end{array}$ & $\begin{array}{l}16 \\
35\end{array}$ & $\begin{array}{l}13 \\
24\end{array}$ & 0.819 & $\begin{array}{l}7 \\
10\end{array}$ & $\begin{array}{l}22 \\
49\end{array}$ & 0.422 & $\begin{array}{l}15 \\
22\end{array}$ & $\begin{array}{l}14 \\
37\end{array}$ & 0.252 \\
\hline NTH & $\begin{array}{l}\text { Low } \\
\text { High }\end{array}$ & $\begin{array}{l}18 \\
33\end{array}$ & $\begin{array}{l}18 \\
19\end{array}$ & 0.273 & $\begin{array}{l}6 \\
11\end{array}$ & $\begin{array}{l}30 \\
41\end{array}$ & 0.600 & $\begin{array}{l}14 \\
23\end{array}$ & $\begin{array}{l}22 \\
29\end{array}$ & 0.665 \\
\hline$X R C C$ & $\begin{array}{l}\text { Low } \\
\text { High }\end{array}$ & $\begin{array}{l}24 \\
27\end{array}$ & $\begin{array}{l}16 \\
21\end{array}$ & 0.829 & $\begin{array}{l}4 \\
13\end{array}$ & $\begin{array}{l}36 \\
35\end{array}$ & 0.043 & $\begin{array}{l}19 \\
18\end{array}$ & $\begin{array}{l}21 \\
30\end{array}$ & 0.390 \\
\hline OGGI & $\begin{array}{l}\text { Low } \\
\text { High }\end{array}$ & $\begin{array}{l}39 \\
12\end{array}$ & $\begin{array}{l}31 \\
6\end{array}$ & 0.437 & $\begin{array}{l}12 \\
5\end{array}$ & $\begin{array}{l}58 \\
13\end{array}$ & 0.308 & $\begin{array}{l}31 \\
6\end{array}$ & $\begin{array}{l}39 \\
12\end{array}$ & 0.437 \\
\hline POLB & $\begin{array}{l}\text { Low } \\
\text { High }\end{array}$ & $\begin{array}{l}32 \\
19\end{array}$ & $\begin{array}{l}22 \\
15\end{array}$ & 0.826 & $\begin{array}{l}11 \\
6\end{array}$ & $\begin{array}{l}43 \\
28\end{array}$ & 0.753 & $\begin{array}{l}26 \\
11\end{array}$ & $\begin{array}{l}28 \\
23\end{array}$ & 0.185 \\
\hline STING & $\begin{array}{l}\text { Low } \\
\text { High }\end{array}$ & $\begin{array}{l}37 \\
14\end{array}$ & $\begin{array}{l}32 \\
5\end{array}$ & 0.189 & $\begin{array}{l}15 \\
2\end{array}$ & $\begin{array}{l}55 \\
16\end{array}$ & 0.323 & $\begin{array}{l}28 \\
9\end{array}$ & $\begin{array}{l}41 \\
10\end{array}$ & 0.610 \\
\hline IRF3 & $\begin{array}{l}\text { Low } \\
\text { High }\end{array}$ & $\begin{array}{l}21 \\
30\end{array}$ & $\begin{array}{l}14 \\
23\end{array}$ & 0.827 & $\begin{array}{l}6 \\
11\end{array}$ & $\begin{array}{l}29 \\
42\end{array}$ & 0.675 & $\begin{array}{l}15 \\
22\end{array}$ & $\begin{array}{l}20 \\
31\end{array}$ & NA \\
\hline CD4 & $\begin{array}{l}\text { Low } \\
\text { High }\end{array}$ & $\begin{array}{l}25 \\
26\end{array}$ & $\begin{array}{l}16 \\
21\end{array}$ & 0.667 & $\begin{array}{l}10 \\
7\end{array}$ & $\begin{array}{l}31 \\
40\end{array}$ & 0.260 & $\begin{array}{l}16 \\
21\end{array}$ & $\begin{array}{l}25 \\
26\end{array}$ & 0.667 \\
\hline CD8 & $\begin{array}{l}\text { Low } \\
\text { High }\end{array}$ & $\begin{array}{l}33 \\
18\end{array}$ & $\begin{array}{l}18 \\
19\end{array}$ & 0.1892 & $\begin{array}{l}10 \\
7\end{array}$ & $\begin{array}{l}41 \\
30\end{array}$ & 0.936 & $\begin{array}{l}19 \\
18\end{array}$ & $\begin{array}{l}32 \\
19\end{array}$ & 0.382 \\
\hline CD20 & $\begin{array}{l}\text { Low } \\
\text { High }\end{array}$ & $\begin{array}{l}43 \\
8\end{array}$ & $\begin{array}{l}21 \\
16\end{array}$ & 0.007 & $\begin{array}{l}13 \\
4\end{array}$ & $\begin{array}{l}51 \\
20\end{array}$ & 0.699 & $\begin{array}{l}28 \\
9\end{array}$ & $\begin{array}{l}36 \\
15\end{array}$ & 0.636 \\
\hline PD-LI & $\begin{array}{l}\text { Low } \\
\text { High }\end{array}$ & $\begin{array}{l}38 \\
13\end{array}$ & $\begin{array}{l}29 \\
8\end{array}$ & 0.8016 & $\begin{array}{l}13 \\
4\end{array}$ & $\begin{array}{l}54 \\
17\end{array}$ & 0.971 & $\begin{array}{l}28 \\
9\end{array}$ & $\begin{array}{l}39 \\
12\end{array}$ & NA \\
\hline PD-L2 & $\begin{array}{l}\text { Low } \\
\text { High }\end{array}$ & $\begin{array}{l}27 \\
24\end{array}$ & $\begin{array}{l}20 \\
17\end{array}$ & NA & $\begin{array}{l}14 \\
3\end{array}$ & $\begin{array}{l}33 \\
38\end{array}$ & 0.008 & $\begin{array}{l}23 \\
14\end{array}$ & $\begin{array}{l}24 \\
27\end{array}$ & 0.197 \\
\hline
\end{tabular}

\section{Correlation analysis among IHC makers}

In order to investigate the biological relationship between the IHC markers and clinical characteristics, we generated a correlogram (Figure 4). Strikingly, we found that pol $\beta$ was negatively correlated with $\mathrm{CD} 4+\mathrm{T}$ cells $(\mathrm{r}=-0.288$, $p=0.007)$ and positively correlated with $\mathrm{CD} 20+\mathrm{B}$ cells $(\mathrm{r}=0.225, p=0.036)$. Moreover, STING is negatively correlated with $\operatorname{LVI}(\mathrm{r}=-0.252, p=0.02), \mathrm{CD} 20$ is positively correlated with PD-L1 $(\mathrm{r}=0.238, p=0.026)$, grade is negatively correlated with XRCC1 $(\mathrm{r}=-0.215, p=0.044)$, and positively correlated with PD-L2 $(\mathrm{r}=0.284, p=0.008)$, stage $(\mathrm{r}=0.4, p<0.001)$ and LVI $(\mathrm{r}=0.239, p=0.026)$.

\section{Discussion}

Genome instability and mutation is the hallmark of cancer. ${ }^{31}$ On one hand, they can promote the occurrence and development of tumors. On the other hand, a large number of recent basic studies have found that genome instability can further activate innate and adaptive immunity by releasing dangerous signals such as dsDNA and being recognized by pattern recognition receptors such as cGAS-STING pathway. ${ }^{32}$ The result of genomic instability is the initiation of DNA damage repair. ${ }^{16} \mathrm{BER}$ is the most extensive and basic way to repair a large number of base damage. ${ }^{33}$ Therefore, the BER pathway proteins expression level in cancer cells can reflect the level of DNA damage repair in cancer cells to an extent. This study explored the effect of BER and STING pathway proteins on the prognosis of UTUC from the clinical perspective. The main findings are: high expression of IRF3 is associated with better prognosis, regardless of DFS or OS. In addition, high expression of APE1, pol $\beta$ is associated with poor prognosis. CD8 $+\mathrm{T}$ cell infiltration was also found to be a prognostic factor for UTUC, pol $\beta$ is found to be correlated with T cell infiltration.

APE1 is a key protein within the BER pathway as it processes the vast majority of AP sites in the cell. ${ }^{34}$ 


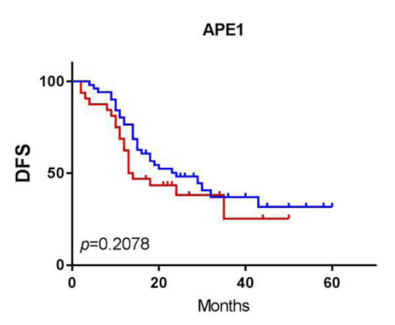

POLB

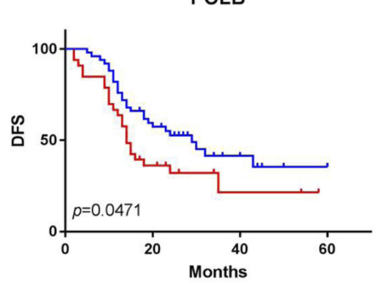

CD8

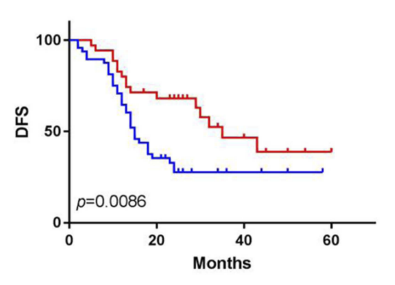

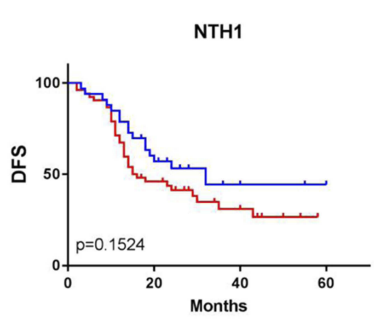

STING

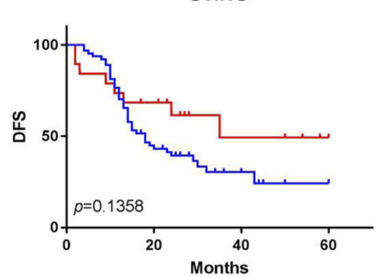

CD20

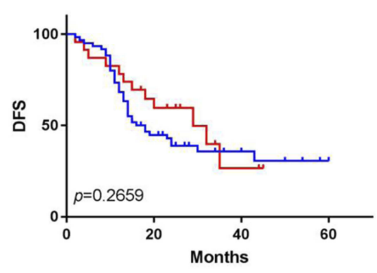

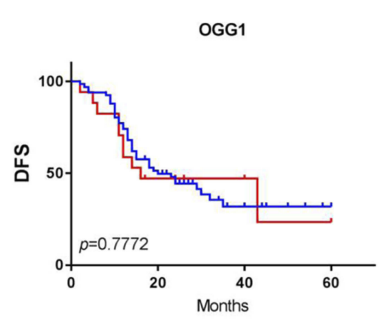

IRF3

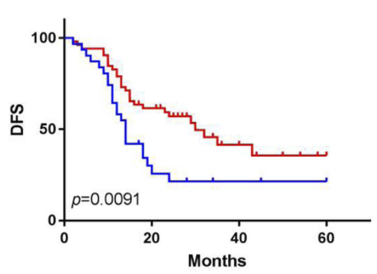

PD-L1

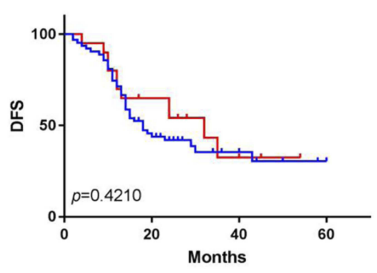

XRCC1

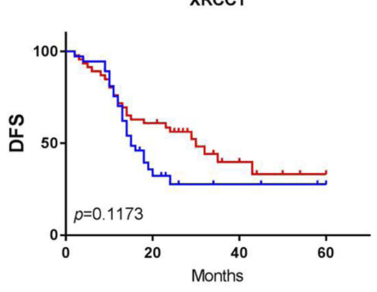

CD4

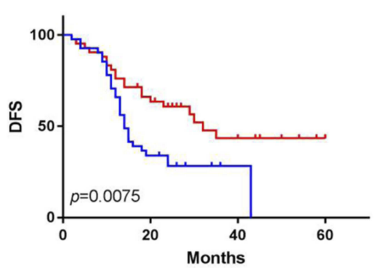

PD-L2

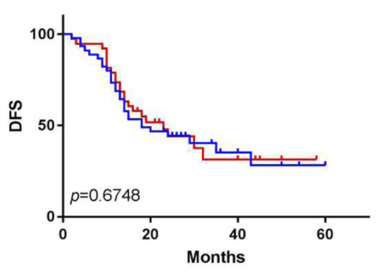

High expression

Figure I Kaplan-Meier survival analysis of DFS in subsets of high- and low-expression groups of the prognostic makers including APEI, NTHI, OGGI, XRCCI, Polß, STING, IRF3, PD-LI, PD-L2, CD4, CD8, CD20 (log-rank test), blue means low expression, red means high expression. Results low expression of IRF3, CD4, CD8, and high expression of pol $\beta$ were associated with shorter DFS.

Amongst BER components, APE1 has been intensively studied for its extensive range of cellular functions. In addition to its known role as the major AP site endonuclease, APE1 also has transcriptional regulatory activity involving redox-mediated modulation of transcription factors, as well as multiple roles in RNA metabolism. ${ }^{35}$ Our previous studies suggested that the high expression of APE1 in lung cancer, liver cancer and gastric cancer is associated with poor prognosis and platinum resistance. ${ }^{27,36,37}$ Jeon $\mathrm{BH}$ also found that the serum APE1 and urine APE1 of patients with bladder cancer were significantly higher than that of normal people, suggesting APE1 to be a potential marker. ${ }^{38,39}$ Consistent with previous studies, our study found that high expression of APE1 was associated with adverse OS; however, the relationship between APE1 and DFS was not found, nor was the difference between APE1 in low-grade and high-grade urothelial cancer, muscle invasion and non-muscle invasion found. The possible explanation is that APE1 itself has no difference between low-grade and high-grade urothelial cancer, muscle invasion and non-muscle invasion in UTUC, or the number of samples is too small to reflect the difference.

$\operatorname{pol} \beta$ is the main polymerase involved in BER, and is responsible for two key activities in the BER pathway: DNA polymerase and 5'-dRP lyase activities. pol $\beta$ is responsible for inserting the correct bases into the DNA backbone of the APE1-cut DNA in the BER pathway and restoring the correct base pairing of the DNA strand. A large number of studies have found that mutations in pol $\beta$ at some key sites are associated with susceptibility to cancer, ${ }^{40,41}$ and some somatic mutations are associated with resistance to platinum treatment. ${ }^{42}$ However, there are few studies on the connection between pol $\beta$ expression and prognosis in tumors. In this study, pol $\beta$ was found to have worse prognosis in patients with high expression of UTUC in terms of protein expression, and it was found to be negatively correlated with tumor-infiltrating $\mathrm{CD} 8+\mathrm{T}$ lymphocytes, the mechanism of which remains to be further studied. 

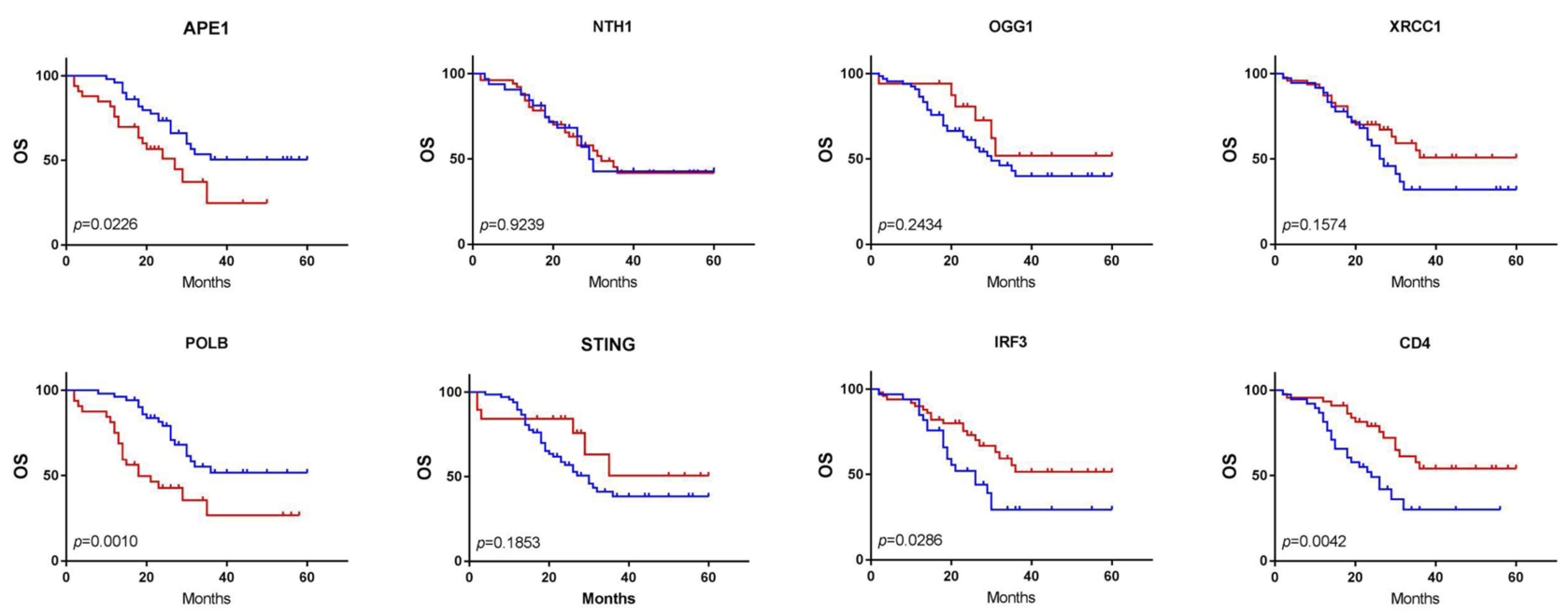

CD8

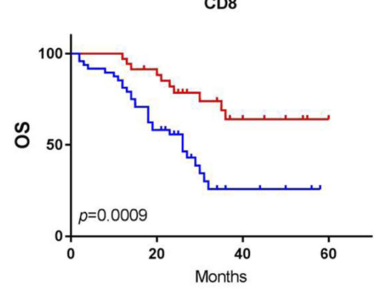

PD-L1

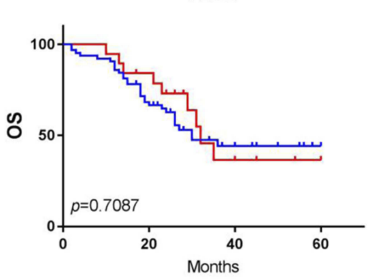

PD-L2

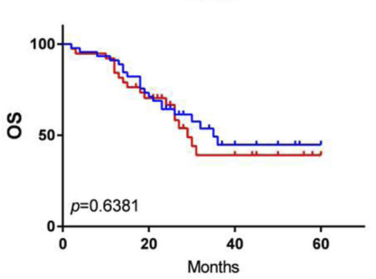

\section{$\square$ High expression $\square$ Low expression}

Figure 2 Kaplan-Meier survival analysis of OS in subsets of high- and low-expression groups of the prognostic makers including APEI, NTHI, OGGI, XRCCI, Pol $\boldsymbol{\beta}$, STING, IRF3, PD-LI, PD-L2, CD4, CD8, CD20 (log-rank test), blue means low expression, red means high expression. Results high expression of APEI, polß, and low expression of CD4, CD8, IRF3 were correlated with poor OS.

Table 3 Predictive factors for DFS in UTUC patients

\begin{tabular}{|c|c|c|c|c|c|c|}
\hline \multirow[t]{2}{*}{ Variables } & \multicolumn{3}{|c|}{ Univariate } & \multicolumn{3}{|c|}{ Multivariate } \\
\hline & HR & Cl $95 \%$ & $p$-value & HR & Cl $95 \%$ & $p$-value \\
\hline Age, $<65, \geq 65$ & 1.128 & $0.628-2.027$ & 0.687 & & & \\
\hline LVI & 1.925 & $1.002-3.697$ & 0.049 & & & \\
\hline STAGE & 1.423 & $0.802-2.526$ & 0.228 & & & \\
\hline GRADE & 1.502 & $0.727-3.102$ & 0.272 & & & \\
\hline NTHI & 1.291 & $0.717-2.324$ & 0.394 & & & \\
\hline $\mathrm{XRCCI}$ & 0.645 & $0.367-1.133$ & 0.127 & & & \\
\hline APEI & 1.321 & $0.734-2.373$ & 0.352 & & & \\
\hline OGGI & 1.103 & $0.55 I-2.209$ & $0.78 I$ & & & \\
\hline POLB & 1.733 & $0.991-3.032$ & 0.054 & & & \\
\hline STING & 0.514 & $0.230-1.149$ & 0.105 & & & \\
\hline IRF3 & 0.486 & $0.276-0.853$ & 0.012 & $0.45 I$ & $0.243-0.837$ & 0.024 \\
\hline CD4 & 0.468 & $0.263-0.835$ & 0.010 & & & \\
\hline CD8 & 0.435 & $0.235-0.805$ & 0.008 & 0.522 & $0.295-0.926$ & 0.014 \\
\hline CD20 & 0.530 & $0.434-1.537$ & 0.530 & & & \\
\hline
\end{tabular}




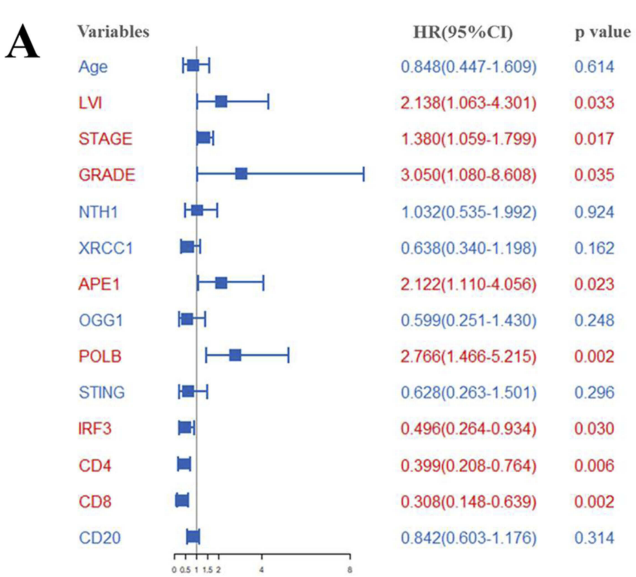

B

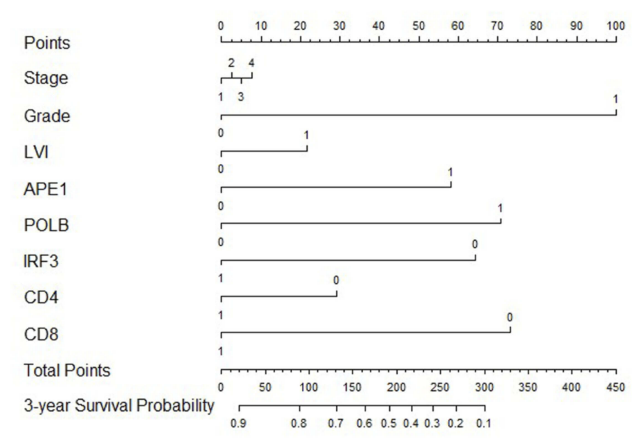

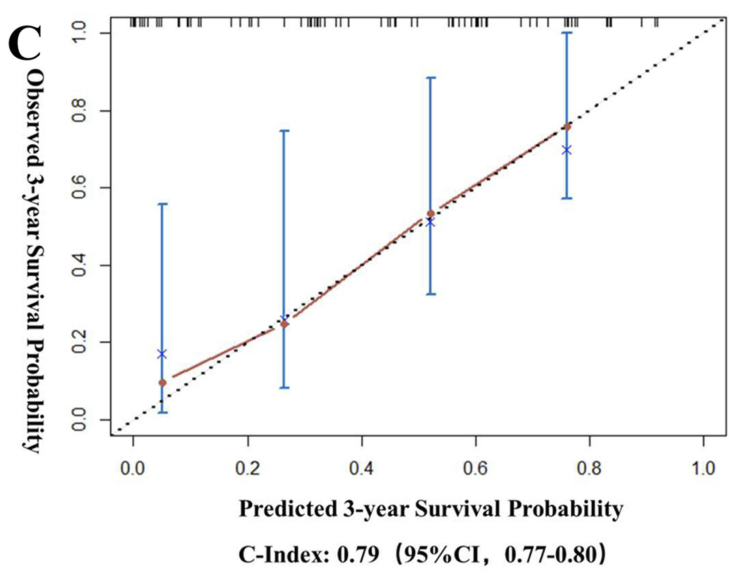

D

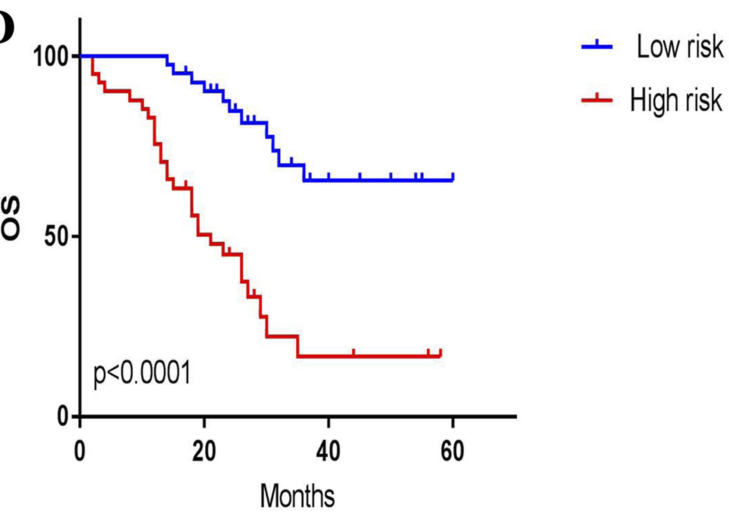

Figure 3 DNA damage, IRF3 and tumor-infiltrating lymphocytes are an independent prognostic factor of UTUC. (A) Forest plot indicating HR (blue squares) and corresponding $95 \% \mathrm{Cl}$ (blue horizontal lines) of IHE makers and clinical characteristics for OS. In figure $3 A$ blue represents $p>0.05$, and red represents $p<0.05$. (B) Internal cross-validated adaptive elastic-net model for OS is illustrated by a nomogram. A straight upward line to the "Points" axis is drawn for each individual patient clinical characteristic and marker expression, following a straight downward line to the "Total Points" axis, the "Linear Predictor" and the corresponding "3-Year Overall Survival Probability". (C) Calibration plots demonstrate virtually ideal predictions for 3-year OS, c-index equals 0.79. (D) Kaplan-Meier survival analysis of OS in subsets of high- and low-risk groups, according to the Internal cross-validated adaptive elastic-net model.

Table 4 Predictive factors for OS in UTUC patients

\begin{tabular}{|c|c|c|c|c|c|c|}
\hline \multirow[t]{2}{*}{ Variables } & \multicolumn{3}{|c|}{ Univariate } & \multicolumn{3}{|c|}{ Multivariate } \\
\hline & HR & Cl $95 \%$ & $p$-value & HR & Cl $95 \%$ & $p$-value \\
\hline Age, $<65, \geq 65$ & 0.848 & $0.447-1609$ & 0.614 & & & \\
\hline LVI & 2.138 & $1.063-4.30 \mid$ & 0.033 & & & \\
\hline STAGE & 1.380 & $1.059-1.799$ & 0.017 & & & \\
\hline GRADE & 3.050 & $1.080-8.608$ & 0.035 & 3.059 & $|.08|-8.66 \mid$ & 0.035 \\
\hline NTHI & 1.032 & $0.535-1.991$ & 0.924 & & & \\
\hline $\mathrm{XRCCI}$ & 0.638 & $0.340-1.198$ & 0.162 & & & \\
\hline APEI & 2.122 & $1.110-4.056$ & 0.023 & 1.932 & $1.005-3.714$ & 0.048 \\
\hline OGGI & 0.599 & $0.25 I-1.430$ & 0.248 & & & \\
\hline POLB & 2.766 & $1.466-5.215$ & 0.002 & 2.620 & $1.373-5.000$ & 0.003 \\
\hline STING & 0.628 & $0.263-1.501$ & 0.296 & & & \\
\hline IRF3 & 0.496 & $0.264-0.934$ & 0.030 & 0.539 & $0.277-1.049$ & 0.069 \\
\hline CD4 & 0.399 & $0.208-0.764$ & 0.006 & & & \\
\hline CD8 & 0.308 & $0.148-0.639$ & 0.002 & 0.323 & $0.151-0.693$ & 0.004 \\
\hline CD20 & 0.842 & $0.603-1.176$ & 0.314 & & & \\
\hline
\end{tabular}




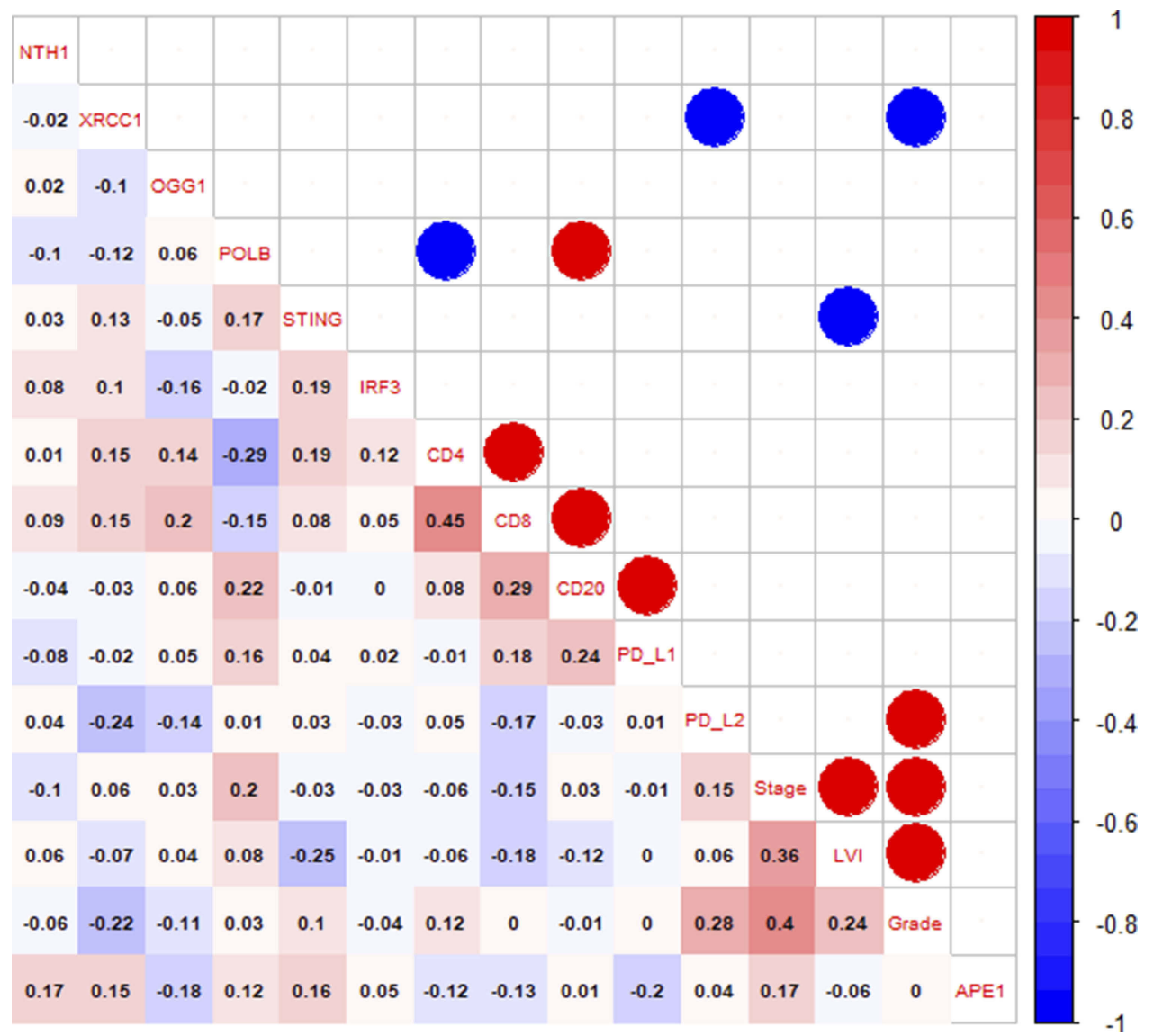

Figure $4 \mathrm{~A}$ correlogram of marker panel values is shown. Correlation coefficients $(r)$ for all markers are given in the lower triangle. Colored circles indicate statistically significant correlations. Size and color intensity of the circles are related to the correlation coefficients. Blue color represents negative and red color positive correlations.

IRF3 is constitutively expressed in most cell types; it has been extensively studied as a major transcription factor regulating I-IFN involved in antiviral response. Current studies suggest that IRF3 is also a key molecule in the Toll-like receptor signaling pathway, STING signaling pathway and RIG signaling pathway, inducing important cytokines. Moreover, IRF3 interacts with other transcription factors, coactivators and repressors, including other IRFs, NF-kB p65, Maf-B, $\beta$-catenin, ROR $\gamma$ t or the proapoptotic molecule Bax. ${ }^{43}$ This broadens its capacity to influence different cellular processes such as cell death or metabolism. As the downstream of STING signaling pathway, IRF3 mainly regulates the production of I-IFN. In tumor microenvironment, DNA damage can further induce the production of I-IFN through the activation of IRF3 induced by STING. ${ }^{44}$ In this study, we found that IRF3 was associated with the prognosis of UTUC, but no correlation was found between IRF3 and BER pathway proteins. We speculate this may be related to the activation of IRF3. It is well known that IRF3 is activated by phosphorylation and transferred into the nucleus to mediate the production of I-IFN. Therefore, the total expression level of IRF3 protein is not sufficient to explain its activation status.

TILs are the local histopathological reflection of the host's immune response to cancer cells. Many studies have shown TILs as a good prognostic factor in a variety of tumors (such as breast cancer, rectal cancer, lung cancer, melanoma, etc.). ${ }^{45-47}$ and the presence of TILs can lead to better clinical prognosis. In addition, this TILs-based immune score is more accurate than traditional histology or even MSI status in predicting the prognosis of patients with early colorectal cancer. ${ }^{48}$ There are also studies in bladder cancer suggesting that tumor-infiltrating immune cells, including TINs, TILs and NLR are important markers in predicting the prognosis of bladder cancer patients. TINs and NLR were more likely to be negative predictors, while TILs were favorable in patients with $\mathrm{BC} .{ }^{49}$ In this study, univariate analysis showed that CD4 and CD8 are prognostic factors of DFS and OS, but only CD8 function as an independent prognostic factor after 
multivariate analysis, and high expression CD8 was associated with good prognosis. CD4, CD8 was also found to be associated with pol $\beta$, a possible explanation being DNA repair capacity serves as a key determinant of mutation load. DNA repair-deficient cancers have increased genomic instability, leading to a "mutator phenotype" characterized by the accumulation of mutations. For example, MMR-deficient colorectal cancers not only have 10 to 100 times more somatic mutations compared with MMR-proficient colorectal tumors, but also have prominent lymphocytic infiltration. But pol $\beta$ is negatively correlated with CD4 and positively correlated with $\mathrm{CD} 8$, the underlying mechanism is unclear.

In conclusion, we found that BER protein APE1, pol $\beta$, STING pathway protein IRF3 and CD8+ T cells were associated with the prognosis of UTUC patients, and pol $\beta$ was associated with CD8+ T cells in TME. These positive results provide clinical evidence for recruitment and activation of TILS through STING pathway activated by DNA damage repair. However, further research on mechanisms are still needed to support our study.

\section{Disclosure}

The authors report no conflicts of interest in this work.

\section{References}

1. Roupret M, Babjuk M, Comperat E, et al. European Association of urology guidelines on upper urinary tract urothelial carcinoma: 2017 update. Eur Urol. 2018;73(1):111-122. doi:10.1016/j. eururo.2017.07.036

2. Moussa S, Yafi FA, El-Hakim A, et al. Outcome of surgical treatment of patients with upper versus lower urinary tract urothelial carcinoma: stage-by-stage comparison. Urol Int. 2010;84(1):50-55. doi:10.1159/ 000273466

3. Lughezzani G, Burger M, Margulis V, et al. Prognostic factors in upper urinary tract urothelial carcinomas: a comprehensive review of the current literature. Eur Urol. 2012;62(1):100-114. doi:10.1016/j. eururo.2012.02.030

4. Clements T, Messer JC, Terrell JD, et al. High-grade ureteroscopic biopsy is associated with advanced pathology of upper-tract urothelial carcinoma tumors at definitive surgical resection. J Endourol. 2012;26 (4):398-402. doi:10.1089/end.2011.0426

5. Mbeutcha A, Roupret M, Kamat AM, et al. Prognostic factors and predictive tools for upper tract urothelial carcinoma: a systematic review. World J Urol. 2017;35(3):337-353. doi:10.1007/s00345-0161826-2

6. Fridman WH, Galon J, Pages F, Tartour E, Sautes-Fridman C, Kroemer G. Prognostic and predictive impact of intra- and peritumoral immune infiltrates. Cancer Res. 2011;71(17):5601-5605. doi:10.1158/ 0008-5472.CAN-11-1316

7. Fridman WH, Pages F, Sautes-Fridman C, Galon J. The immune contexture in human tumours: impact on clinical outcome. Nat Rev Cancer. 2012;12(4):298-306. doi:10.1038/nrc3245

8. Zitvogel L, Galluzzi L, Kepp O, Smyth MJ, Kroemer G. Type I interferons in anticancer immunity. Nat Rev Immunol. 2015;15 (7):405-414. doi:10.1038/nri3845
9. Musella M, Manic G, De Maria R, Vitale I, Sistigu A. Type-Iinterferons in infection and cancer: unanticipated dynamics with therapeutic implications. Oncoimmunology. 2017;6(5):e1314424. doi:10.1080/2162402X.2017.1314424

10. Ishikawa H, Ma Z, Barber GN. STING regulates intracellular DNAmediated, type I interferon-dependent innate immunity. Nature. 2009;461(7265):788-792. doi:10.1038/nature08476

11. Deng L, Liang H, Xu M, et al. STING-dependent cytosolic DNA sensing promotes radiation-induced type I interferon-dependent antitumor immunity in immunogenic tumors. Immunity. 2014;41(5):843852. doi:10.1016/j.immuni.2014.10.019

12. Corrales L, McWhirter SM, Dubensky TW Jr, Gajewski TF. The host STING pathway at the interface of cancer and immunity. $J$ Clin Invest. 2016;126(7):2404-2411. doi:10.1172/JCI86892

13. Sun L, Wu J, Du F, Chen X, Chen ZJ. Cyclic GMP-AMP synthase is a cytosolic DNA sensor that activates the type I interferon pathway. Science. 2013;339:5. doi:10.1126/science. 1232458

14. Wu J, Sun L, Chen X, et al. Cyclic GMP-AMP is an endogenous second messenger in innate immune signaling by cytosolic DNA. Science. 2013;339(6121):826-830. doi:10.1126/science.1229963

15. Ablasser A, Goldeck M, Cavlar T, et al. cGAS produces a 2'-5'-linked cyclic dinucleotide second messenger that activates STING. Nature. 2013;498(7454):380-384. doi:10.1038/nature12306

16. Tubbs A, Nussenzweig A. Endogenous DNA damage as a source of genomic instability in cancer. Cell. 2017;168(4):644-656. doi:10.1016/j.cell.2017.01.002

17. Chatterjee N, Walker GC. Mechanisms of DNA damage, repair, and mutagenesis. Environ Mol Mutagen. 2017;58(5):235-263. doi:10.1002/ em. 22087

18. Mirza-Aghazadeh-Attari M, Darband SG, Kaviani M, et al. DNA damage response and repair in colorectal cancer: defects, regulation and therapeutic implications. DNA Repair (Amst). 2018;69:34-52. doi:10.1016/j.dnarep.2018.07.005

19. Nombela P, Lozano R, Aytes A, Mateo J, Olmos D, Castro E. BRCA2 and other DDR genes in prostate cancer. Cancers. 2019;11 (3). doi:10.3390/cancers 11030352

20. Teo MY, Seier K, Ostrovnaya I, et al. Alterations in DNA damage response and repair genes as potential marker of clinical benefit from PD-1/PD-L1 blockade in advanced urothelial cancers. J Clin Oncol. 2018;36(17):1685-1694. doi:10.1200/JCO.2017.75.7740

21. Teo MY, Bambury RM, Zabor EC, et al. DNA damage response and repair gene alterations are associated with improved survival in patients with platinum-treated advanced urothelial carcinoma. Clin Cancer Res. 2017;23(14):3610-3618. doi:10.1158/1078-0432.CCR-16-2520

22. Mitra S, Hazra TK, Roy R, et al. Complexities of DNA base excision repair in mammalian cells. Mol Cells. 1997;7(3):305-312.

23. Krokan HE, Nilsen H, Skorpen F, Otterlei M, Slupphaug G. Base excision repair of DNA in mammalian cells. FEBS Lett. 2000;476(12):73-77. doi:10.1016/s0014-5793(00)01674-4

24. Robertson $\mathrm{AB}$, Klungland $\mathrm{A}$, Rognes $\mathrm{T}$, Leiros I. DNA repair in mammalian cells: base excision repair: the long and short of it. Cell Mol Life Sci. 2009;66(6):981-993. doi:10.1007/s00018-009-8736-z

25. Wallace SS. Base excision repair: a critical player in many games. $D N A$ Repair (Amst). 2014;19:14-26. doi:10.1016/j.dnarep.2014.03.030

26. Poletto M, Legrand AJ, Dianov GL. DNA base excision repair: the Achilles' heel of tumour cells and their microenvironment? Curr Pharm Des. 2017;23(32):4758-4772. doi:10.2174/13816 12823666170710123602

27. Wang D, Xiang DB, Yang XQ, et al. APE1 overexpression is associated with cisplatin resistance in non-small cell lung cancer and targeted inhibition of APE1 enhances the activity of cisplatin in A549 cells. Lung Cancer. 2009;66(3):298-304. doi:10.1016/j.lungcan.2009.02.019

28. Hudson AL, Parker NR, Khong P, et al. Glioblastoma recurrence correlates with increased APE1 and polarization toward an immuno-suppressive microenvironment. Front Oncol. 2018;8:314. doi:10.3389/ fonc. 2018.00314 
29. Albertella MR, Lau A, O'Connor MJ. The overexpression of specialized DNA polymerases in cancer. DNA Repair (Amst). 2005;4 (5):583-593. doi:10.1016/j.dnarep.2005.01.005

30. Kallioniemi OP, Wagner U, Kononen J, Sauter G. Tissue microarray technology for high-throughput molecular profiling of cancer. Hum Mol Genet. 2001;10(7):657-662. doi:10.1093/hmg/10.7.657

31. Hanahan D, Weinberg RA. Hallmarks of cancer: the next generation. Cell. 2011;144(5):646-674. doi:10.1016/j.cell.2011.02.013

32. Chatzinikolaou G, Karakasilioti I, Garinis GA. DNA damage and innate immunity: links and trade-offs. Trends Immunol. 2014;35 (9):429-435. doi:10.1016/j.it.2014.06.003

33. Freidberg EC, Wood RD, Walker GC, Siede W. DNA Repair and Mutagenesis. Washington (DC): ASM Press; 2006.

34. Nakamura J, Swenberg JA. Endogenous apurinic/apyrimidinic sites in genomic DNA of mammalian tissues. Cancer Res. 1999;59(11):25222526 .

35. Li M, Wilson DM 3rd. Human apurinic/apyrimidinic endonuclease 1. Antioxid Redox Signal. 2014;20(4):678-707. doi:10.1089/ars.2013.5492

36. Kan G, Dong W. The expression of PD-L1 APE1 and P53 in hepatocellular carcinoma and its relationship to clinical pathology. Eur Rev Med Pharmacol Sci. 2015;19(16):3063-3071.

37. Qing Y, Li Q, Ren T, et al. Upregulation of PD-L1 and APE1 is associated with tumorigenesis and poor prognosis of gastric cancer Drug Des Devel Ther. 2015;9:901-909. doi:10.2147/DDDT.S75152

38. Shin JH, Choi S, Lee YR, et al. APE1/Ref-1 as a serological biomarker for the detection of bladder cancer. Cancer Res Treat. 2015;47(4):823-833. doi:10.4143/crt.2014.074

39. Choi S, Shin JH, Lee YR, et al. Urinary APE1/Ref-1: a potential bladder cancer biomarker. Dis Markers. 2016;2016:7276502. doi:10.1155/2016/ 7276502

40. Guo Z, Zheng L, Dai H, Zhou M, Xu H, Shen B. Human DNA polymerase beta polymorphism, Arg137Gln, impairs its polymerase activity and interaction with PCNA and the cellular base excision repair capacity. Nucleic Acids Res. 2009;37(10):3431-3441. doi:10.1093/nar/gkp201
41. Yamtich J, Nemec AA, Keh A, Sweasy JB. A germline polymorphism of DNA polymerase beta induces genomic instability and cellular transformation. PLoS Genet. 2012;8(11):e1003052. doi:10.1371/journal. pgen. 1003052

42. Nemec AA, Abriola L, Merkel JS, et al. DNA polymerase beta germline variant confers cellular response to cisplatin therapy. Mol Cancer Res. 2017;15(3):269-280. doi:10.1158/1541-7786. MCR-16-0227-T

43. Ysebrant de Lendonck L, Martinet V, Goriely S. Interferon regulatory factor 3 in adaptive immune responses. Cell Mol Life Sci. 2014;71 (20):3873-3883. doi:10.1007/s00018-014-1653-9

44. Kato K, Omura H, Ishitani R, Nureki O. Cyclic GMP-AMP as an endogenous second messenger in innate immune signaling by cytosolic DNA. Annu Rev Biochem. 2017;86:541-566. doi:10.1146/ annurev-biochem-061516-044813

45. Fridman WH, Zitvogel L, Sautes-Fridman C, Kroemer G. The immune contexture in cancer prognosis and treatment. Nat Rev Clin Oncol. 2017;14(12):717-734. doi:10.1038/nrclinonc.2017.101

46. Green AR, Aleskandarany MA, Ali R, et al. Clinical impact of tumor DNA repair expression and T-cell infiltration in breast cancers. Cancer Immunol Res. 2017;5(4):292-299. doi:10.1158/2326-6066. CIR-16-0195

47. Bremnes RM, Busund L-T, Kilvær TL, et al. The role of tumorinfiltrating lymphocytes in development, progression, and prognosis of non-small cell lung cancer. J Thoracic Oncol. 2016;11(6):789800. doi:10.1016/j.jtho.2016.01.015

48. Mlecnik B, Bindea G, Angell HK, et al. Integrative analyses of colorectal cancer show immunoscore is a stronger predictor of patient survival than microsatellite instability. Immunity. 2016;44(3):698711. doi:10.1016/j.immuni.2016.02.025

49. Liu K, Zhao K, Wang L, Sun E. The prognostic values of tumorinfiltrating neutrophils, lymphocytes and neutrophil/lymphocyte rates in bladder urothelial cancer. Pathol Res Pract. 2018;214 (8):1074-1080. doi:10.1016/j.prp.2018.05.010
OncoTargets and Therapy

\section{Publish your work in this journal}

OncoTargets and Therapy is an international, peer-reviewed, open access journal focusing on the pathological basis of all cancers, potential targets for therapy and treatment protocols employed to improve the management of cancer patients. The journal also focuses on the impact of management programs and new therapeutic

Submit your manuscript here: https://www.dovepress.com/oncotargets-and-therapy-journ agents and protocols on patient perspectives such as quality of life, adherence and satisfaction. The manuscript management system is completely online and includes a very quick and fair peer-review system, which is all easy to use. Visit http://www.dovepress.com/ testimonials.php to read real quotes from published authors. 